\title{
CHARACTERIZING PIVOT SPRINKLERS \\ USING AN EXPERIMENTAL IRRIGATION MACHINE
}

by

\author{
Playán, E. ${ }^{1}$, Garrido, S. ${ }^{2}$, Faci, J. M. ${ }^{2}$ and Galán, A. ${ }^{1}$
}

\section{ADDITIONAL KEYWORDS}

precipitation, rotating plate, fixed plate, wind drift and evaporation losses

\section{ABSTRACT}

In this work, a fixed spray plate sprinkler (FSPS) and two rotating spray plate sprinklers (RSPS) were compared in terms of wetted diameter, wind drift and evaporation losses (WDEL), static water precipitation pattern and dynamic water application profile. An experimental irrigation machine reproducing a pivot section was constructed and used to perform experiments in static and dynamic (linear displacement) modes. Water application from FSPS often resulted in a bi-modal pattern, while RSPS produced bell-shaped or triangular patterns. At a nozzle elevation of $2.4 \mathrm{~m}$ and an operating pressure of $140 \mathrm{kPa}$ the wetted diameter was $1.6 \mathrm{~m}$ larger for the RSPS than for the FSPS. The differences between the two RSPS amounted to $0.5 \mathrm{~m}$ on the average. Reducing the nozzle elevation from 2.4 to $1.0 \mathrm{~m}$ resulted in a $2.6 \mathrm{~m}$ decrease in the wetted diameter. The use of RSPS may result in reduced surface runoff losses, due to the increased wetted diameter and the reduced peak precipitation rate. WDEL for

\footnotetext{
${ }^{1}(\bowtie)$ Dept. Genetics and Plant Production, Laboratory for Agronomy and Environment (DGA- CSIC), Estación Experimental de Aula Dei, CSIC, Apdo. 202, 50080 Zaragoza, Spain.playan@eead.csic.es

2 Department of Soils and Irrigation, Laboratory for Agronomy and Environment (DGA-CSIC), Centro de Tecnología e Investigación Agroalimentaria, DGA, Apdo. 727, 50080 Zaragoza, Spain. jfaci@aragob.es
} 
RSPS were statistically related to wind speed, although no significant differences were found between both types of RSPS or between the two nozzle elevations. According to the experimental results, reducing the nozzle elevation will not result in reduced WDEL, but will increase the chances for runoff. 


\section{INTRODUCTION}

In many new sprinkler irrigated projects the fields result adequate for pivot irrigation, due to its large size and mild slope. This irrigation system can attain a considerable cost reduction as compared to solid-set sprinkler irrigation (Keller and Bliesner, 1990). Pivots are often preferred by farmers due to its robustness and automation possibilities (Dechmi et al., 2003). One potential problem of pivot irrigation is the high application rate at the lateral end, which may exceed the soil infiltration rate. Under this situation runoff and erosion can occur and the uniformity of infiltrated water can be severely affected (Keller and Bliesner, 1990). This problem can be alleviated by the appropriate selection of the pivot length and the use of adequate soil tillage and mulching techniques.

In the last decades a number of changes have been introduced in the sprinklers used for pivot irrigation. While the initial pivot designs used high-pressure impact sprinklers, the energy required to operate these machines rendered them uneconomical (Musick et al., 1988). The next step was to use Fixed Spray Plate Sprinklers (FSPS), which require lower pressure. In these, a vertical water jet formed by the sprinkler nozzle hits a fixed horizontal grooved deflector plate which spreads water in all directions. Kincaid et al. (1996) analysed the drop size distribution resulting from FSPS, and found that drop sizes tended to concentrate in a narrow range of diameters. A few years later, Faci et al. (2001) reported that the water application resulting from an isolated FSPS produces a wetted circular crown. This result is in agreement with the theory of ballistics applied to sprinkler irrigation (Fukui et al., 1980; Carrión et al., 2001), stating that for a given sprinkler set-up the horizontal distance separating the emitter from the landing point of a drop is a function of its diameter (among other variables). Therefore, if the range in drop diameters is small, all drops will land at approximately the same distance from the emitter. Performing simulated overlapping, Faci et al. (2001) reported problems with FSPS uniformity for large overlapping distances (over $5 \mathrm{~m}$ ). These problems are related to the circular crown water application pattern, and are addressed in commercial irrigation machines by using narrow sprinkler spacings, typically of $2.74 \mathrm{~m}(9 \mathrm{ft})$. 
A major change in pivot sprinklers was introduced in the mid 1990's, with the commercialisation of the first Rotating Spray Plate Sprinklers (RSPS). Pressure requirements for RSPS are similar to those of FSPS. The first commercial design was the Nelson Rotator ${ }^{\mathrm{TM}}$ (use of trademarks does not imply endorsement). The characteristic of RSPS is that the deflector plate has a number of curved grooves, which create a momentum on the plate itself. Since the plate is mounted on an axis, it rotates under the effect of the jet, and so do the jets resulting from each groove. Rotator spray sprinklers are manufactured with 4 and 6 grooves, differing in their water application pattern. The drop size distribution for Rotator nozzles was also analysed by Kincaid et al. (1996), who found that the range in drop size diameters was much wider than for FSPS. Faci et al. (2001) used the results of these experiments to present curves of drop size distributions resulting from the $3.8 \mathrm{~mm}, 6.7 \mathrm{~mm}$ and $7.9 \mathrm{~mm}$ nozzle diameters of Rotating and Fixed Plate Spray Sprinklers. The selected spray sprinklers were the Nelson D3000 Sprayhead (FSPS) and the six-groove Nelson R3000 Rotator ${ }^{\mathrm{TM}}$. While the FSPS drops reach $3 \mathrm{~mm}$ in diameter, the RSPS drops are well graded and exceed $6 \mathrm{~mm}$ in diameter. As a consequence, RSPS present a conical water application pattern (Faci et al., 2001), just like a typical impact sprinkler. Since the drop diameters are larger than for FSPS, RSPS produce larger wetted diameters, and therefore can apply the same irrigation depth as FSPS with lower precipitation rates. This characteristic has been experimentally documented (Faci et al., 2001). Sourell et al. (2003) analysed the water application resulting from an isolated four grooved Nelson R3000 Rotator, and performed simulations of overlapping to analyse its applicability to spray boom designs in the conditions of an irrigated area in Germany.

By the end of the 1990's, Senninger introduced the i-Wob standard angle ${ }^{\mathrm{TM}}$, a different design for a RSPS. The rotation of the deflector plate is ensured by the eccentric rotation of the nine-groove deflector plate around a vertical axis. As a result, the rotation is much faster than for the rotator spray sprinklers, and the jets resulting from each groove change their vertical angle continuously.

The objectives of this work were: 1) to construct an experimental irrigation machine reproducing a pivot reach, with adjustable nozzle height and lateral speed; and 2) to perform a number of outdoor experiments, both static and dynamic, comparing the 
performance of pivots equipped with an FSPS and two types of RSPS (Rotator and i-Wob). 


\section{MATERIALS AND METHODS}

\section{$\underline{\text { The Experimental Irrigation Machine and Spray Sprinklers }}$}

An experimental irrigation machine was built at the research farm of the Centro de Investigación y Tecnología Agroalimentaria of the Government of Aragón, located in Zaragoza (Spain). The machine consisted of a $26 \mathrm{~m}$ water supply steel pipeline with an internal diameter of $80 \mathrm{~mm}$, and with connections for spray sprinklers located on the top of the pipeline at a spacing of $1 \mathrm{~m}$. Five spray sprinklers, separated $6 \mathrm{~m}$, were installed in the machine, hanging from the supply pipeline through a $180^{\circ}$ elbow (Figs. 1, 2). The pipeline was supported by an overhead structure of steel beams and cables that maintained its horizontality, just like in any commercial pivot irrigation machine. The main difference with a pivot reach is that the experimental machine was not suspended from its sides, but from the middle point. In fact, the pipeline and its supporting structure were hung from a pyramidal steel tower located at its centre. The tower was built using steel I-beams, minimising the obstruction to the water drop trajectories. The suspension mechanism was designed to avoid momentum transfer from the pipeline to the tower, and to ensure self stabilization and horizontality. These provisions were made to ensure risk-free performance under the strong winds characteristic of Zaragoza. The water supply for the pipeline was through a hose connected to its centre. Manual operation of a cable reel permitted changing the elevation of the spray sprinklers from 1.0 to $2.4 \mathrm{~m}$ in a few minutes. These two nozzle elevations are common in many pivot irrigated areas. Higher elevations (about $4 \mathrm{~m}$ ) are frequent in many pivots, particularly in the old designs. The constructive characteristics of the experimental machine did not allow nozzle heights greater than $2.4 \mathrm{~m}$.

The machine was mounted on four steel wheels which sat on two parallel $36 \mathrm{~m}$ long rails (Fig. 1). Two electric engines powered the front and rear wheel sets. A gear system was designed to obtain three different displacement speeds: 20.6, 31.1 and $62.1 \mathrm{~m} \mathrm{~h}^{-1}$. These speeds are within the usual range of lineal speeds at different points of pivot machines. The electrical supply line was attached to the water supply hose, so that in its movement along the rails the machine dragged the water and electricity lines. Machine design was completed with hydraulic and electric control elements. The hydraulic elements included manometers at the water supply and irrigation line, valves, 
and a volumetric water meter located within the tower structure. The electric elements were designed to assure safe operation, particularly under wet outdoor conditions, and included emergency stop buttons close to the moving elements, end-of-rail sensors for automatic stop, and a programmer.

The selected FSPS was the Valmont Spray. The chosen RSPS were the sixgroove Nelson Rotator R3000 and the Senninger i-Wob Standard-Angle. Throughout this work, these will be referred to as Spray, Rotator and i-Wob sprinklers. In all cases three nozzle diameters were used: 3.8, 6.7 and $7.9 \mathrm{~mm}$. These diameters cover the usual range installed in medium sized pivots. The operating pressure was $140 \mathrm{kPa}$, established using Valmont pressure regulators just upstream from each sprinkler.

Experiments were performed with the machine in static and dynamic modes. The static experiments were used to characterize the water application pattern (precipitation as a function of distance across the irrigation lateral) and to simulate dynamic water application. The dynamic experiments were used to estimate the water application profiles (time evolution of the precipitation rate at a given point of the field) and to assess irrigation uniformity.

\section{$\underline{\text { Static experiments }}$}

A total of 39 experiments were performed with the machine stopped at the middle of the railways (Table 1). The experiments involved the use of two nozzle elevations (1.0 and $2.4 \mathrm{~m}$ ), the three types of sprinklers, three nozzle diameters and different wind conditions, ranging from 0.19 to $4.93 \mathrm{~m} \mathrm{~s}^{-1}$. In order to restrict the experimental combinations, the effect of nozzle elevation was only analysed for the Rotator sprinkler. For the trials with Rotator and i-Wob sprinklers, low and high wind conditions were selected (separated by a threshold of $1.5 \mathrm{~m} \mathrm{~s}^{-1}$ ). In the Spray sprinkler only low-wind experiments were performed.

The catch cans, made from transparent plastic, were conical in shape and graduated in $1 \mathrm{~mm}\left(1 \mathrm{Lm}^{-2}\right)$ increments up to a maximum of $40 \mathrm{~mm}$. These characteristics made them quick and easy to read and store. Figure 2a presents the catch can set-up used for the static experiments with Rotator and i-Wob sprinklers. In the 
figure, wetted circumferences with a $8 \mathrm{~m}$ radius are drawn around each sprinkler to illustrate the overlapping. The catch cans formed a 25 x 4 network (with a spacing of $1.0 \times 1.5 \mathrm{~m}$ ) located in a fully overlapped area. One of the four catch can lines was moved to the other side of the rails in order to minimize possible interferences in the drop trajectory induced by the presence of the tower. The set-up used for Spray was completed with two additional lines (Fig. 2b), following the findings of Faci et al. (2001), who reported difficulties to characterize the water application pattern created by this type of sprinklers using a limited number of catch cans. These difficulties are derived from their peculiar circular crown wetted area pattern, the high precipitation recorded in such a small area, and the fact that the jets do not rotate, and therefore its drops tend to land at a given point.

In each experiment, the water meter and a wind run totaliser were read at the time the irrigation lateral was connected. Irrigation proceeded until a number of catch cans exceeded $30 \mathrm{~mm}$. At this time, irrigation was stopped and the final water volume and wind run were recorded. Following these readings, the wind speed and the discharged irrigation volume were determined. The wetted diameter was computed from the distance separating the extreme non-zero catch can readings. Precipitation at each catch can was determined from the irrigation depth ( $\mathrm{mm}$ ) and the total irrigation time (h). The experimental catch can lines (four for RSPS and six for FSPS) were averaged, and the resulting figures were used to determine the catch can irrigation volume (multiplying the catch can depth by the catch can spacing of $1.5 \mathrm{~m}^{2}$ ). In each experiment, the Wind Drift and Evaporation Losses (WDEL, \%) were determined as:

$$
\text { WDEL }(\%)=\frac{(\text { discharged volume }- \text { catch can volume })}{\text { discharged volume }} 100
$$

WDEL represents the percentage of the water emitted by the sprinklers which never reached the soil surface of the field, and therefore was either drifted to other locations or evaporated.

For each type of sprinkler, nozzle elevation and diameter, the catch can readings were averaged for the experiments performed under different wind conditions. As a result, average water application patterns were produced for the experimental conditions 
(precipitation vs. distance across the irrigation line). Two steps were taken to generalise these results: 1) the right and left sides of the water distribution curve were averaged to minimise the effect of the wind on the shape of the water pattern; and 2) each precipitation value was divided by the distance separating the sprinklers and multiplied by the desired sprinkler spacings. Two spacings were considered in this work: $2.74 \mathrm{~m}$ (9 ft) typical of the Spray sprinkler (occasionally used in Rotator and i-Wob pivots); and $5.47 \mathrm{~m}$ (18 ft) typical of Rotator and i-Wob sprinklers. With these adjustments, the experimental data can be used to reproduce the static water application pattern resulting from any sprinkler spacing.

The static experimental results can be used to simulate the water application profile resulting from a given lineal machine speed. For this purpose, distances across the irrigation machine are replaced by the corresponding times. The first nonzero precipitation is set to time 0 , and the following times are increased by the ratio of $0.5 \mathrm{~m}$ to the lineal speed.

\section{Dynamic Experiments}

During the dynamic experiments, the machine travels along the railways. The starting point of the machine displacement is depicted in Figure 3 as position A. When irrigation starts, the machine irrigates three rows of catch cans in the first part of the experiment, devoted to the characterisation of water application. Before reaching position B (the end of the experiment), the machine travels over two matrices of catch cans, in what constitutes the uniformity experiment.

The water application experiment is based on the fact that the catch cans located under the wetted diameter of the machine at the beginning of irrigation do not receive a full irrigation depth. Water application in this area starts from zero at the cans on the right side of Figure 3 to the full irrigation depth just left of the initial wetted diameter. The difference between two adjacent catch cans represents the water application during the time the machine takes to cover the distance separating them. Following this principle, the water application profile (precipitation vs. time) could be reproduced by: 1) averaging the three rows of catch cans; 2) taking differences between adjacent average catch can readings; 3) determining the time required for the machine to cover 
the $1 \mathrm{~m}$ distance separating adjacent catch cans; 4) using that time to transform catch can depth into precipitation; and 5) using cumulative time from the first non-zero precipitation as the abscissa of the plot, and precipitation as the ordinate.

As the machine approaches position B, it irrigates two matrices of 7 by 4 catch cans. The variability in this set of 56 fully irrigated catch cans was used to estimate irrigation uniformity using the Coefficient of Uniformity (CU, \%) (Merriam and Keller, 1978):

$\mathrm{CU}=\left(1-\frac{\sum_{\mathrm{i}=1}^{56}\left|\mathrm{z}_{\mathrm{i}}-\mathrm{m}\right|}{56 \overline{\mathrm{z}_{\mathrm{i}}}}\right) 100$

where $z_{i}$ represents the depth of water in each catch can $(\mathrm{mm})$ and $m$ is the average depth. 


\section{RESULTS AND DISCUSSION}

\section{$\underline{\text { Static Experiments }}$}

Table 1 presents the results of the static experiments. For any combination of sprinkler and nozzle elevation, the wetted diameter grows with the nozzle diameter. Table 2 presents average values among all the experiments performed with different wind conditions. At an elevation of $2.4 \mathrm{~m}$, the RSPS's (Rotator and i-Wob) present an average improvement of $1.6 \mathrm{~m}$ in diameter as compared to the FSPS. Overall, the i-Wob sprinkler wetted diameter was $0.5 \mathrm{~m}$ larger than for Rotator. However, this average figure hides a large advantage on the smallest nozzle diameters, and small disadvantages for the other two diameters. Reducing the nozzle elevation from 2.4 to $1.0 \mathrm{~m}$ in Rotator resulted in a $2.6 \mathrm{~m}$ decrease in the wetted diameter. These differences in wetted diameter produced appreciable differences in average precipitation. As a consequence, narrow water applications result in large average precipitations, which may lead to surface runoff water losses and soil erosion. The experimental results for the maximum precipitation (Table 1 ) indicate that there is a very large variability between experiments in the Spray sprinkler. This variability was previously reported by Faci et al. (2001), and attributed to the fact that the sprinkler jets tend to land at fixed locations, and may or may not be captured by the catch cans. The results of the two RSPS operating at $2.4 \mathrm{~m}$ are very similar and show little experimental variability. Finally, reducing the nozzle elevation of the Rotator results in an increase in the maximum precipitation rate.

Analyses of variance were performed on the experimental data to characterize the effect of the type of sprinkler and the nozzle diameter on wetted diameter and precipitation (average and maximum). The analysis corresponding to the three sprinklers at a nozzle elevation of $2.4 \mathrm{~m}$ confirmed the significant effect of both variables (p-values less than 0.05), except for the type of sprinkler in the case of average precipitation. A similar analysis was performed for the Rotator sprinkler at the two nozzle elevations. A significant effect of nozzle diameter and elevation on precipitation and wetted diameter was detected. 
The average experimental water application pattern is presented in Figure 4 for different combinations of sprinkler, nozzle height and nozzle diameter. These results confirm the findings of Faci et al. (2001), regarding the often bi-modal water application pattern resulting from Spray sprinklers, and the bell-shaped or triangular application resulting from Rotator sprinklers. The water distribution pattern of i-Wob can be compared to that of Rotator, since both fall in the category of RSPS. The differences in water application between both types of sprinklers are hard to appreciate, due to the experimental conditions (mainly the disturbing effect of wind speed and direction). However, the i-Wob sprinkler seems to result in a more triangular water application than the Rotator sprinkler. Fig. 4 also presents the comparison between 1.0 and 2.4 nozzle elevations for the Rotator nozzle. Lowering the nozzle results in a narrower and taller water application pattern.

These water application patterns were used to simulate symmetrical water application profiles, considering (as an example) a machine speed of $30 \mathrm{~m} \mathrm{~h}^{-1}$ (Fig. 5). The typical commercial sprinkler spacings were used (2.74 m for FSPS and $5.47 \mathrm{~m}$ for RSPS). Nozzle elevation was $2.40 \mathrm{~m}$, except for the case of the Rotator sprinkler, for which results are also presented at an elevation of $1.0 \mathrm{~m}$. Figure 5 permits to compare water application to soil infiltration rate curves, thus leading to an estimation of the surface runoff losses resulting from each combination of soil, sprinkler, nozzle diameter, spacing, machine velocity and nozzle elevation. Elaborating pivot sprinkler recommendations for a given soil will require evaluation of a number of application profile curves, since each nozzle diameter will be used at a range of radial distances, and will therefore work in a different range of linear pivot speeds. Although producing this information would be time consuming, the limiting factor would be the availability of the infiltration curves, which should be obtained using rainfall simulators. Factors such as water quality (salinity) and mulching have been reported to play a relevant effect on sprinkler irrigation infiltration (López-Bruna and Aragüés, 1995). Therefore, additional research will be required to establish a procedure to integrate all these variables into pivot design for a specific field.

The last column in Table 1 presents the wind drift and evaporation losses for each experiment. The wind speed ranged from 0.19 to $4.93 \mathrm{~m} \mathrm{~s}^{-1}$, and the WDEL ranged from 0.3 to $8.3 \%$. Figure 6 presents two plots of WDEL vs. wind speed. The first plot 
(Fig. 6a) presents data for the Rotator sprinkler, and compares the two nozzle elevations, including results for the three nozzle diameters. The resulting regression lines are not significantly different, and therefore it can not be concluded (with the available data set) that lowering the sprinklers results in a decrease in WDEL. Further statistical analysis of the original data presented by Faci et al. (2001) supports the same conclusion.

Figure $6 \mathrm{~b}$ presents all data for the three types of sprinklers at an elevation of $2.4 \mathrm{~m}$. The relationship between Spray WDEL and wind speed is poor and nonsignificant, reflecting the abovementioned problems about catch can operation with the Spray sprinkler. More catch cans would have been required to obtain an accurate estimate of the catch can volume (Eq. 1). On the other hand, wind speeds below $1.5 \mathrm{~m} \mathrm{~s}^{-1}$ were selected in this type of sprinkler, reducing the variability found in Rotator and i-Wob. As a result, the Spray WDEL data can not be considered valuable for comparison with the other sprinklers. The regression lines obtained for Rotator and i-Wob WDEL are not significantly different, and therefore the WDEL resulting from both types of sprinklers can not be distinguished. A similar statistical analysis applied to the results of Spray and Rotator sprinkler WDEL presented by Faci et al. (2001), indicates that both types of sprinklers resulted in just one regression line against wind speed. Experimental evidence suggests that the WDEL - wind speed relationship is independent of the type of sprinkler (Spray, Rotator or i-Wob).

Further research will be required to obtain more firm conclusions in this subject, including daytime / night time evaluation of WDEL, extending the range of the experimental wind speeds and adding additional independent variables to the WDEL regression model (Tarjuelo et al., 2000). Since particular regression lines reflecting differences in nozzle elevation or type of sprinkler could not be statistically supported, the following equation, obtained with Rotator and i-Wob sprinklers at 1.0 and $2.4 \mathrm{~m}$ nozzle elevation is proposed:

$\mathrm{WDEL}=1.55+1.13 \mathrm{U} \quad \mathrm{R}^{2}=0.57 * * *$

Where $U$ is the wind speed $\left(\mathrm{m} \mathrm{s}^{-1}\right)$. 


\section{Dynamic Experiments}

Table 3 presents a summary of the results of the dynamic experiments. The wind speed range is small in comparison with the static experiments $\left(0.02\right.$ to $\left.2.59 \mathrm{~m} \mathrm{~s}^{-1}\right)$. For a given nozzle diameter and machine speed, the differences among average depths are only due to the differences in WDEL. Therefore, large differences can only be obtained when different nozzle diameters and / or machine speeds are compared. The difference between average and maximum depth is already an indicator of irrigation uniformity. The largest differences arise for the Spray sprinkler, where particular catch cans receive up to 2.5 times the average depth. As a consequence, the average CU for Spray is typically low (76.6 \%), as compared to that of Rotator (94.4\%) or i-Wob (92.7 \%). This low Spray uniformity is partly due to the inadequacy of the experimental sprinkler

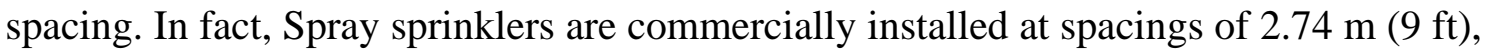
at which the resulting uniformity would be significantly higher (Faci et al., 2001).

The experimental values of CU obtained in this work are slightly lower than the uniformity estimates obtained from simulation of machine movement presented by Faci et al. (2001). For instance, for the machine speed of $31.1 \mathrm{~m} \mathrm{~h}^{-1}$, averaging the three nozzle diameters of the Rotator sprinkler, the experimental CU was $94.1 \%$, sensibly lower than the simulated value of $97.1 \%$. This difference suggests that performing experiments on moving laterals may be required to obtain accurate estimates of irrigation uniformity. No trend could be established between machine speed and irrigation uniformity in the experimental range of machine speeds.

The results of the water application profiles are presented in Figure 7 for a nozzle diameter of $6.7 \mathrm{~mm}$ and a nozzle elevation of $2.4 \mathrm{~m}$. Water application profiles were estimated from the static and dynamic experiments. The large variability in the results of the dynamic experiment required a moving average operation (with a span of 3 elements) in order to obtain smooth results. In the figure, the dynamic profiles are compared with the static profiles obtained from averaging all available experiments with wind speeds below $1.5 \mathrm{~m} \mathrm{~s}^{-1}$ (the experimental wind speeds were $0.89,0.22$ and $1.05 \mathrm{~m} \mathrm{~s}^{-1}$ for Spray, Rotator and i-Wob, respectively). The curves reveal similar patterns between both estimation procedures, although the dynamic experiments result 
in larger variability, particularly in the Spray sprinkler, in which five estimates of precipitation are negative. Similarities are larger for Rotator and i-Wob, although the dynamic results show areas in which the precipitation curve seems to be erratic. This may be due to the effect of the wind, which can be relevant in some instances. For instance, a wind spell can temporarily displace the mass of falling drops back and forth along the machine displacement. Such a displacement could be detected by the experimental procedure, due to the small time step required to cover the distance separating two catch cans. 


\section{CONCLUSIONS}

A FSPS (the Valmont Spray) and two RSPS (The Nelson Rotator R3000 and the Senninger i-Wob Standard-Angle) were evaluated in this work in terms of wetted diameter, water application and WDEL. An experimental irrigation machine reproducing pivot irrigation was constructed and applied for this purpose, using nozzle diameters of 3.8, 6.7 and $7.9 \mathrm{~mm}$. The conclusions of this study are:

- At the same nozzle elevation (2.4 m) and operating pressure (140 kPa), both RSPSs obtained larger wetted diameters than the FSPS. This difference in wetted diameter was $1.6 \mathrm{~m}$ on the average of the experimental nozzle diameters and wind conditions. This improvement in wetted diameter resulted in a decreased average precipitation. The differences between both RSPS were less relevant, amounting to $0.5 \mathrm{~m}$ in favour of the i-Wob sprinkler. This average value showed ample differences among nozzle diameters. Reducing the nozzle elevation from 2.4 to 1.0 m resulted in a 2.6 $m$ reduction in wetted diameter, and a corresponding increase in average precipitation.

- WDEL ranged between 0.3 to $8.3 \%$ of the irrigation water. In the case of the FSPS the losses could not be related to the wind speed, due the difficulty of reproducing the catch can irrigation volume in this type of sprinklers, and to the narrow range in experimental wind speeds. However, in the case of the RSPSs a linear regression model based on wind speed explained $57 \%$ of the variability in WDEL. No differences could be established between both RSPSs or between the two nozzle elevations. As a consequence, in the experimental conditions, lowering the sprinklers resulted in increased chances for surface runoff and no positive effect on WDEL.

- The average CU for the RSPS at a sprinkler spacing of $6 \mathrm{~m}$, an operating pressure of $140 \mathrm{kPa}$ and a nozzle elevation of $2.4 \mathrm{~m}$ was $94.4 \%$ for Rotator and $92.7 \%$ for i-Wob. These uniformities are very adequate for pivot irrigation.

- A method was proposed to estimate the water application profiles from the dynamic experiments. This method is based on the differences in catch can readings between consecutive cans located under the machine at the onset of irrigation and displacement. The resulting water application profiles showed high spatial 
variability. This method resulted useful to prove the validity of simulating these curves from the static water application and the machine velocity.

- Runoff protection is better ensured with RSPS than with FSPS, although differences are not particularly large. Lowering the nozzles does increase the chances for runoff, and has not been proven to reduce WDEL in the experimental conditions. Crop and crop residues management may play a significant role in runoff prevention, due to an increase in soil infiltration. The use of tillage implements that increase surface storage can be also an important practise to avoid runoff.

- The results of this study should be considered as exploratory and design oriented, since a number of factors could affect the validity or the representativity of the results. Although a number of advantages have been recognized to RSPS (as compared to FSPS), the choice of the design irrigation depth, the distribution of nozzle diameters along the pivot, and the determination of the optimum pivot length for each soil seem to be more relevant than the choice of the sprinkler.

\section{ACKNOWLEDGEMENTS}

This research was funded by the CONSI+D of the Government of Aragón (Spain) through grants P08/96 and P028/2000. Thanks are also due to Valmont S.A. (Madrid, Spain) for supplying the experimental spray sprinklers. 


\section{REFERENCES}

Carrión, P., Tarjuelo, J. M. and Montero, J., 2001. SIRIAS: a simulation model for sprinkler irrigation: I. Description of the model. Irrig. Sci., 2001(20):73-84.

Dechmi, F., Playán, E., Faci, J. and Tejero, M., 2003. Analysis of an irrigation district in northeastern Spain: I: Characterisation and water use assessment. Agric. Wat. Manage., 61(2003):75-92.

Faci, J. M., Salvador, R., Playán, E. and Sourell, H., 2001. A comparison of fixed and rotating spray plate sprinklers. J. Irrig. and Drain. Engrg., ASCE, 127(4):224-233.

Fukui, Y., Nakanishi, K. and Okamura, S., 1980. Computer evaluation of sprinkler irrigation uniformity. Irrig. Sci., 2:23-32.

Keller, J. and Bliesner, R. D., 1990. Sprinkle and trickle irrigation. Van Nostrand Reinhold, New York, NY. 652 pp.

Kincaid, D. C., Solomon, K. H. and Oliphant, J. C., 1996. Drop size distributions for irrigation sprinklers. Trans. ASAE, 39(3):839-845.

López-Bruna, D. and Aragüés, R., 1995. Estabilidad estructural de cinco suelos de Monegros II regados con un simulador de lluvia: efecto de la calidad del agua y del acolchado. Invest. Agr.: Prot. Prod. Veg., 10(3):441-462.

Merriam, J. L. and Keller, J., 1978. Farm irrigation system evaluation: a guide for management. Utah State University, Logan, Utah. 271 pp.

Musick, J. T., Pringle, F. B. and Walker, J. W., 1988. Sprinkler and furrow irrigation trends in the Texas High Plains. Applied Engineering in Agriculture, 4(1):46-52.

Sourell, H., Faci, J. and Playán, E., 2003. Performance of rotating spray plate sprinklers in indoor experiments. J. Irrig. and Drain. Engrg., ASCE, 129(5):376-380. 
Tarjuelo, J. M., Ortega, J. F., Montero, J. and de Juan, J. A., 2000. Modelling evaporation and drift losses in irrigation with medium size impact sprinklers under semi-arid conditions. Agric. Wat. Manage., 43(2000):263-284. 


\section{LIST OF TABLES}

Table 1. Characteristics and main results of the static field experiments.

Table 2. Average wetted diameter $(\mathrm{m})$, average precipitation $\left(\mathrm{mm} \mathrm{h}^{-1}\right)$ and average maximum precipitation $\left(\mathrm{mm} \mathrm{h}^{-1}\right)$ resulting from static field experiments with different types of sprinklers, nozzle elevations and diameters.

Table 3. Characteristics and main results of the dynamic field experiments. The nozzle height was $2.4 \mathrm{~m}$ in all cases. 
Table 1. Characteristics and main results of the static field experiments.

\begin{tabular}{|c|c|c|c|c|c|c|c|}
\hline $\begin{array}{l}\text { Nozzle } \\
\text { Height } \\
\text { (m) }\end{array}$ & $\begin{array}{c}\text { Sprinkler } \\
\text { Type }\end{array}$ & $\begin{array}{c}\text { Nozzle } \\
\text { Diameter } \\
(\mathrm{mm})\end{array}$ & $\begin{array}{l}\text { Wind } \\
\text { Speed } \\
\left(\mathrm{m} \mathrm{s}^{-1}\right)\end{array}$ & $\begin{array}{l}\text { Wetted } \\
\text { Diameter } \\
\text { (m) }\end{array}$ & $\begin{array}{c}\text { Average } \\
\text { Precipitation } \\
\left(\mathrm{mm} \mathrm{h}^{-1}\right)\end{array}$ & $\begin{array}{c}\text { Maximum } \\
\text { Precipitation } \\
\left(\mathrm{mm} \mathrm{h}^{-1}\right)\end{array}$ & $\begin{array}{c}\text { WDEL } \\
(\%)\end{array}$ \\
\hline \multirow{28}{*}{2.4} & \multirow{6}{*}{ Spray } & \multirow{2}{*}{3.8} & 0.82 & 14 & 7.4 & 13.5 & 2.3 \\
\hline & & & 0.94 & 13 & 8.3 & 17.1 & 3.6 \\
\hline & & \multirow{2}{*}{6.7} & 0.62 & 16 & 18.3 & 83.6 & 7.6 \\
\hline & & & 0.87 & 17 & 18.3 & 47.2 & 7.1 \\
\hline & & \multirow{2}{*}{7.9} & 0.67 & 18 & 24.6 & 51.4 & 2.9 \\
\hline & & & 1.17 & 17 & 26.2 & 61.0 & 5.2 \\
\hline & \multirow{11}{*}{ Rotator } & \multirow{3}{*}{3.8} & 0.75 & 13 & 7.6 & 11.5 & 3.0 \\
\hline & & & 1.06 & 15 & 6.1 & 9.9 & 5.5 \\
\hline & & & 3.67 & 14 & 6.8 & 11.8 & 7.2 \\
\hline & & \multirow{4}{*}{6.7} & 0.27 & 18 & 18.0 & 31.9 & 2.7 \\
\hline & & & 0.48 & 18 & 18.5 & 39.1 & 3.2 \\
\hline & & & 1.93 & 18 & 17.6 & 34.3 & 4.4 \\
\hline & & & 4.93 & 20 & 19.1 & 36.6 & 8.1 \\
\hline & & \multirow{4}{*}{7.9} & 0.71 & 19 & 24.9 & 44.7 & 0.6 \\
\hline & & & 1.33 & 20 & 24.0 & 42.0 & 1.3 \\
\hline & & & 1.94 & 18 & 25.5 & 44.7 & 2.9 \\
\hline & & & 2.46 & 19 & 24.2 & 41.9 & 3.3 \\
\hline & \multirow{11}{*}{ i-Wob } & \multirow{4}{*}{3.8} & 0.54 & 15 & 7.7 & 15.1 & 2.9 \\
\hline & & & 0.59 & 15 & 7.3 & 13.7 & 1.4 \\
\hline & & & 3.13 & 16 & 7.4 & 14.4 & 4.2 \\
\hline & & & 4.24 & 17 & 6.0 & 16.0 & 4.4 \\
\hline & & \multirow{3}{*}{6.7} & 0.19 & 18 & 17.4 & 32.4 & 2.9 \\
\hline & & & 0.59 & 19 & 18.5 & 35.8 & 2.7 \\
\hline & & & 2.42 & 18 & 17.7 & 31.8 & 5.2 \\
\hline & & \multirow{4}{*}{7.9} & 1.14 & 19 & 24.8 & 48.4 & 5.0 \\
\hline & & & 1.19 & 18 & 26.1 & 47.2 & 0.7 \\
\hline & & & 3.87 & 19 & 23.2 & 41.5 & 6.2 \\
\hline & & & 4.13 & 19 & 22.7 & 43.9 & 8.3 \\
\hline \multirow{11}{*}{1.0} & \multirow{11}{*}{ Rotator } & \multirow{3}{*}{3.8} & 0.90 & 12 & 8.7 & 14.2 & 1.9 \\
\hline & & & 1.48 & 12 & 8.5 & 14.5 & 1.0 \\
\hline & & & 4.50 & 11 & 9.3 & 16.5 & 6.0 \\
\hline & & \multirow{4}{*}{6.7} & 0.52 & 16 & 21.9 & 36.3 & 3.1 \\
\hline & & & 0.75 & 16 & 20.2 & 33.4 & 0.3 \\
\hline & & & 1.95 & 16 & 19.8 & 37.1 & 4.2 \\
\hline & & & 2.52 & 16 & 21.2 & 44.0 & 3.1 \\
\hline & & \multirow{4}{*}{7.9} & 0.86 & 16 & 29.4 & 49.6 & 2.5 \\
\hline & & & 1.01 & 16 & 30.9 & 47.4 & 1.3 \\
\hline & & & 3.29 & 15 & 28.2 & 56.3 & 6.5 \\
\hline & & & 4.19 & 17 & 29.6 & 65.2 & 4.2 \\
\hline
\end{tabular}


Table 2. Average wetted diameter $(\mathrm{m})$, average precipitation $\left(\mathrm{mm} \mathrm{h}^{-1}\right)$ and average maximum precipitation $\left(\mathrm{mm} \mathrm{h}^{-1}\right)$ resulting from static field experiments with different types of sprinklers, nozzle elevations and diameters.

\begin{tabular}{ccrrrr}
\cline { 2 - 5 } & $\begin{array}{c}\text { Nozzle Diameter } \\
(\mathrm{mm})\end{array}$ & $\begin{array}{c}\text { Spray } \\
2.4 \mathrm{~m}\end{array}$ & $\begin{array}{r}\text { Rotator } \\
2.4 \mathrm{~m}\end{array}$ & $\begin{array}{r}\text { i-Wob } \\
2.4 \mathrm{~m}\end{array}$ & $\begin{array}{c}\text { Rotator } \\
1.0 \mathrm{~m}\end{array}$ \\
\hline Average Wetted & 3.8 & 13.5 & 14.0 & 15.8 & 11.7 \\
Diameter $(\mathrm{m})$ & 6.7 & 16.5 & 18.5 & 18.3 & 16.0 \\
& 7.9 & 17.5 & 19.0 & 18.8 & 16.0 \\
\hline Average & 3.8 & 7.9 & 6.8 & 7.1 & 8.8 \\
Precipitation & 6.7 & 18.3 & 18.3 & 17.9 & 20.8 \\
$\left(\mathrm{~mm} \mathrm{~h}^{-1}\right)$ & 7.9 & 25.4 & 24.7 & 24.2 & 29.5 \\
\hline Average Maximum & 3.8 & 15.3 & 11.1 & 14.8 & 15.1 \\
Precipitation & 6.7 & 65.4 & 35.4 & 33.3 & 37.7 \\
$\left(\mathrm{~mm} \mathrm{~h}^{-1}\right)$ & 7.9 & 56.2 & 43.3 & 45.3 & 54.6 \\
\hline
\end{tabular}


Table 3. Characteristics and main results of the dynamic field experiments. The nozzle height was $2.4 \mathrm{~m}$ in all cases.

\begin{tabular}{ccccccc}
\hline $\begin{array}{c}\text { Machine } \\
\text { speed } \\
\left(\mathrm{m} \mathrm{h}^{-1}\right)\end{array}$ & $\begin{array}{c}\text { Sprinkler } \\
\text { Type }\end{array}$ & $\begin{array}{c}\text { Nozzle } \\
\text { Diameter } \\
(\mathrm{mm})\end{array}$ & $\begin{array}{c}\text { Wind } \\
\text { Speed } \\
\left(\mathrm{m} \mathrm{s}^{-1}\right)\end{array}$ & $\begin{array}{c}\text { Average } \\
\text { Depth } \\
(\mathrm{mm})\end{array}$ & $\begin{array}{c}\text { Maximum } \\
\text { Depth } \\
(\mathrm{mm})\end{array}$ & $\begin{array}{c}\text { CU } \\
(\%)\end{array}$ \\
\hline \multirow{3}{*}{20.6} & Spray & 7.9 & 2.59 & 20.6 & 29 & 86.0 \\
\cline { 2 - 7 } & Rotator & 7.9 & 1.64 & 21.9 & 24 & 95.7 \\
\cline { 2 - 7 } & i-Wob & 7.9 & 0.09 & 22.6 & 28 & 93.9 \\
& & 3.8 & 1.67 & 4.3 & 7 & 84.0 \\
& Spray & 6.7 & 0.89 & 9.7 & 24 & 59.0 \\
\cline { 3 - 7 } 31.1 & & 7.9 & 0.78 & 15.2 & 24 & 74.5 \\
& Rotator & 6.8 & - & 4.1 & 6 & 92.9 \\
& & 7.9 & 0.22 & 11.8 & 15 & 93.3 \\
& & 3.8 & 0.31 & 16.5 & 18 & 96.2 \\
\hline \multirow{3}{*}{62.1} & i-Wob & 6.7 & 1.05 & 10.7 & 14 & 93.4 \\
& & 7.9 & 0.70 & 15.1 & 19 & 94.4 \\
\cline { 2 - 7 } & Spray & 7.9 & 0.02 & 6.8 & 11 & 79.4 \\
\cline { 2 - 7 } & Rotator & 7.9 & 2.03 & 7.9 & 9 & 94.0 \\
\hline
\end{tabular}




\section{LIST OF FIGURES}

Figure 1. Diagram of the central area and right wing of the experimental irrigation machine, presented in front and plan views. The catch can set-up corresponds to that presented in Figure $2 a$.

Figure 2. Schematic representation of the experimental set up for the static experiments. Different catch can distributions were used for Rotator and i-Wob (a) and Spray sprinklers (b). Wetted circumferences with a radius of $8 \mathrm{~m}$ are presented around each sprinkler in order to assess sprinkler overlapping.

Figure 3. Schematic representation of the experimental set up for the dynamic experiments. The machine travels from point $A$ to point $B$. The differences in irrigation depth among contiguous catch cans were used to estimate the water application pattern. The variability in irrigation depth at the two 7 by 4 catch can matrices was used to estimate the Coefficient of Uniformity (CU). Wetted circles with a radius of $8 \mathrm{~m}$ are drawn around each sprinkler in order to assess the overlapping.

Figure 4. Average experimental water application patterns resulting from nozzle elevations (E) of $2.4 \mathrm{~m}$ (Spray, Rotator and i-Wob sprinklers) and $1.0 \mathrm{~m}$ (Rotator sprinkler). Results are presented for nozzle diameters of 3.8, 6.7 and $7.9 \mathrm{~mm}$. The experimental nozzle spacing was $6 \mathrm{~m}$.

Figure 5. Simulated water application profiles for different combinations of type of sprinkler, spacing (S) and nozzle elevation (E). Results are presented for the three experimental nozzle diameters. The simulated machine speed was $30 \mathrm{~m} \mathrm{~h}^{-1}$.

Figure 6. Wind Drift and Evaporation Losses (WDEL, \%) as a function of Wind Speed for the static experiments. Results are presented to compare: a) two nozzle elevations for Rotator sprinklers; and b) the three types of sprinklers using a nozzle elevation of $2.4 \mathrm{~m}$. 
Figure 7. Water application profiles for a machine speed of $31.1 \mathrm{~m} \mathrm{~h}^{-1}$ derived from the static and dynamic experiments, for Spray, Rotator and i-Wob sprinklers equipped with $6.7 \mathrm{~mm}$ nozzles and located at an elevation of $2.4 \mathrm{~m}$ over the soil surface. For each type of spray sprinkler, the available static experiments with wind speeds lower than $1.5 \mathrm{~m} \mathrm{~s}^{-1}$ were averaged and the result was used for simulation purposes. 
Figure 1. Diagram of the central area and right wing of the experimental irrigation machine, presented in front and plan views. The catch can set-up corresponds to that presented in Figure $2 a$.

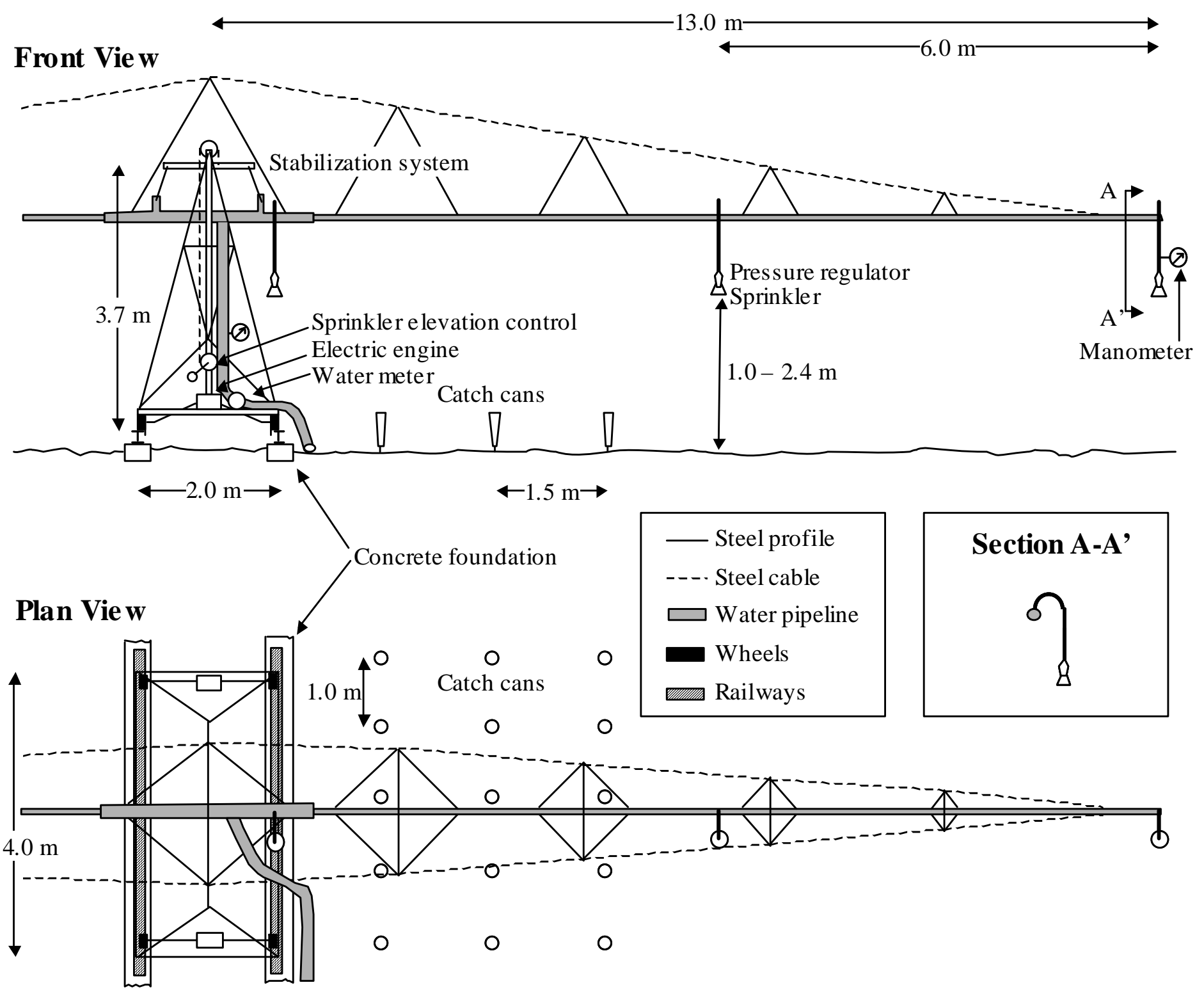


Figure 2. Schematic representation of the experimental set up for the static experiments. Different catch can distributions were used for Rotator and i-Wob (a) and Spray sprinklers (b). Wetted circumferences with a radius of $8 \mathrm{~m}$ are drawn around each sprinkler in order to assess sprinkler overlapping.

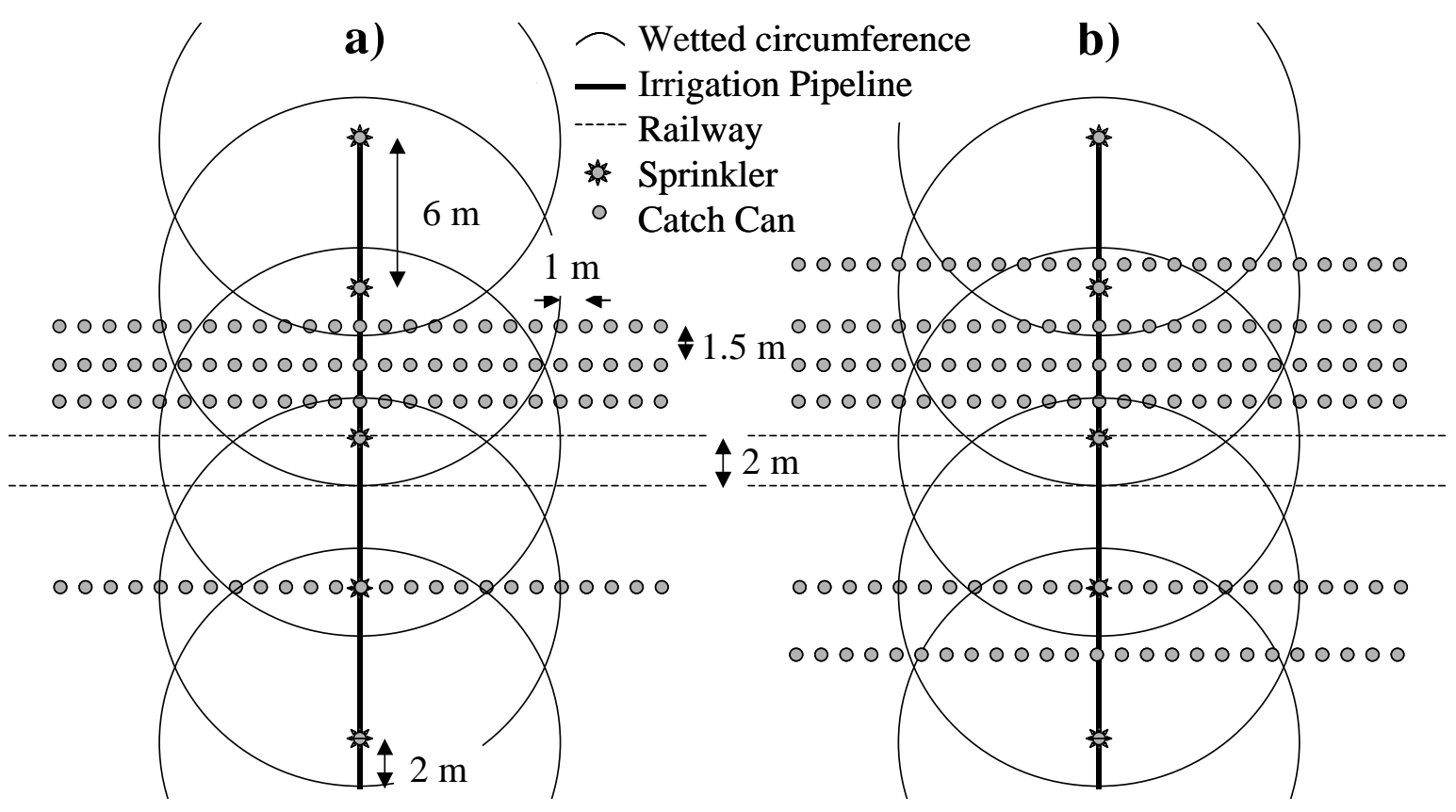


Figure 3. Schematic representation of the experimental set up for the dynamic experiments. The machine travels from point $A$ to point $B$. The differences in irrigation depth among contiguous catch cans were used to estimate the water application pattern. The variability in irrigation depth at the two 7 by 4 catch can matrices was used to estimate the Coefficient of Uniformity (CU). Wetted circles with a radius of $8 \mathrm{~m}$ are drawn around each sprinkler in order to assess the overlapping.

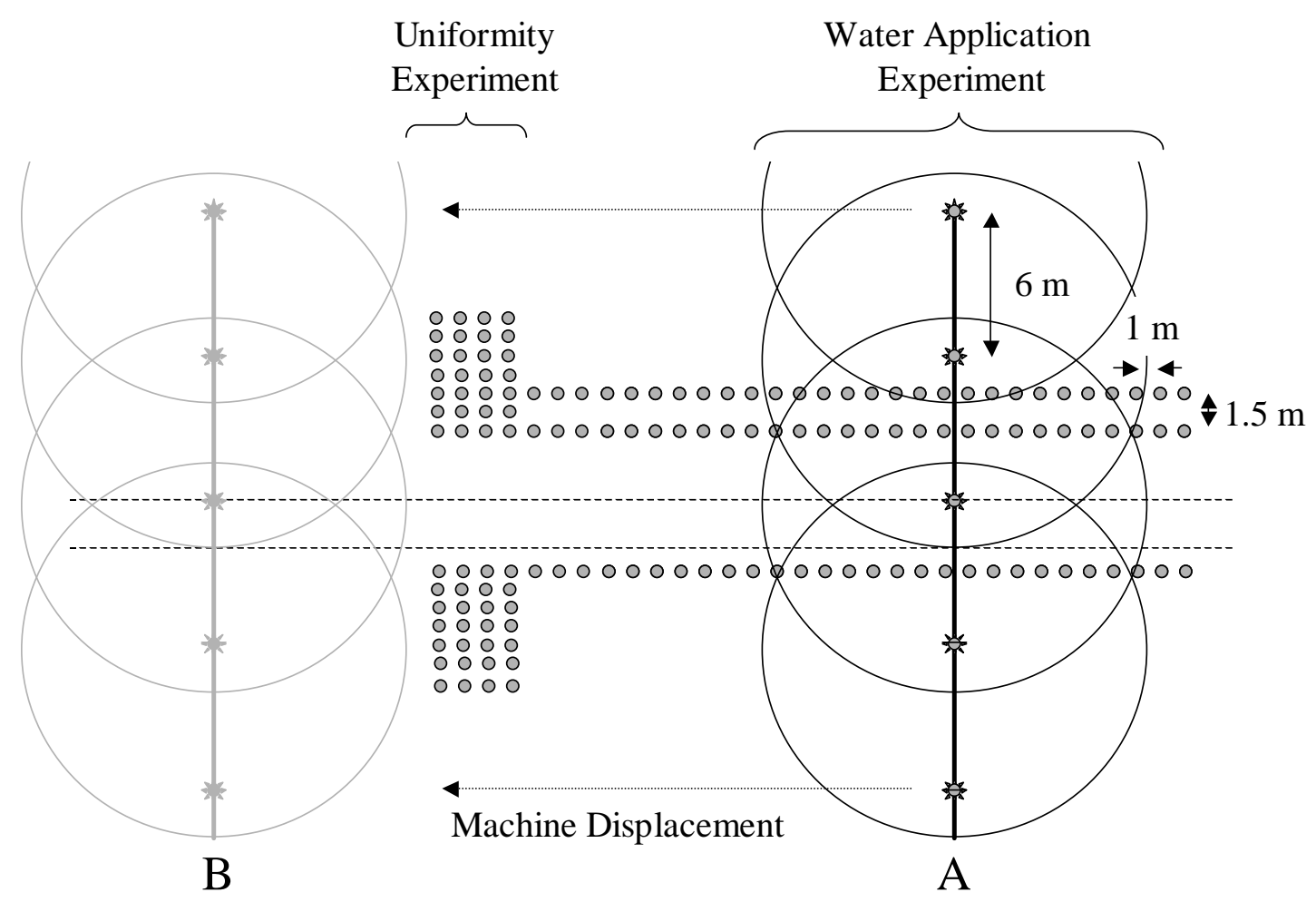


Figure 4. Average experimental water application patterns resulting from nozzle elevations (E) of $2.4 \mathrm{~m}$ (Spray, Rotator and i-Wob sprinklers) and $1.0 \mathrm{~m}$ (Rotator sprinkler). Results are presented for nozzle diameters of 3.8, 6.7 and $7.9 \mathrm{~mm}$. The experimental nozzle spacing was $6 \mathrm{~m}$.
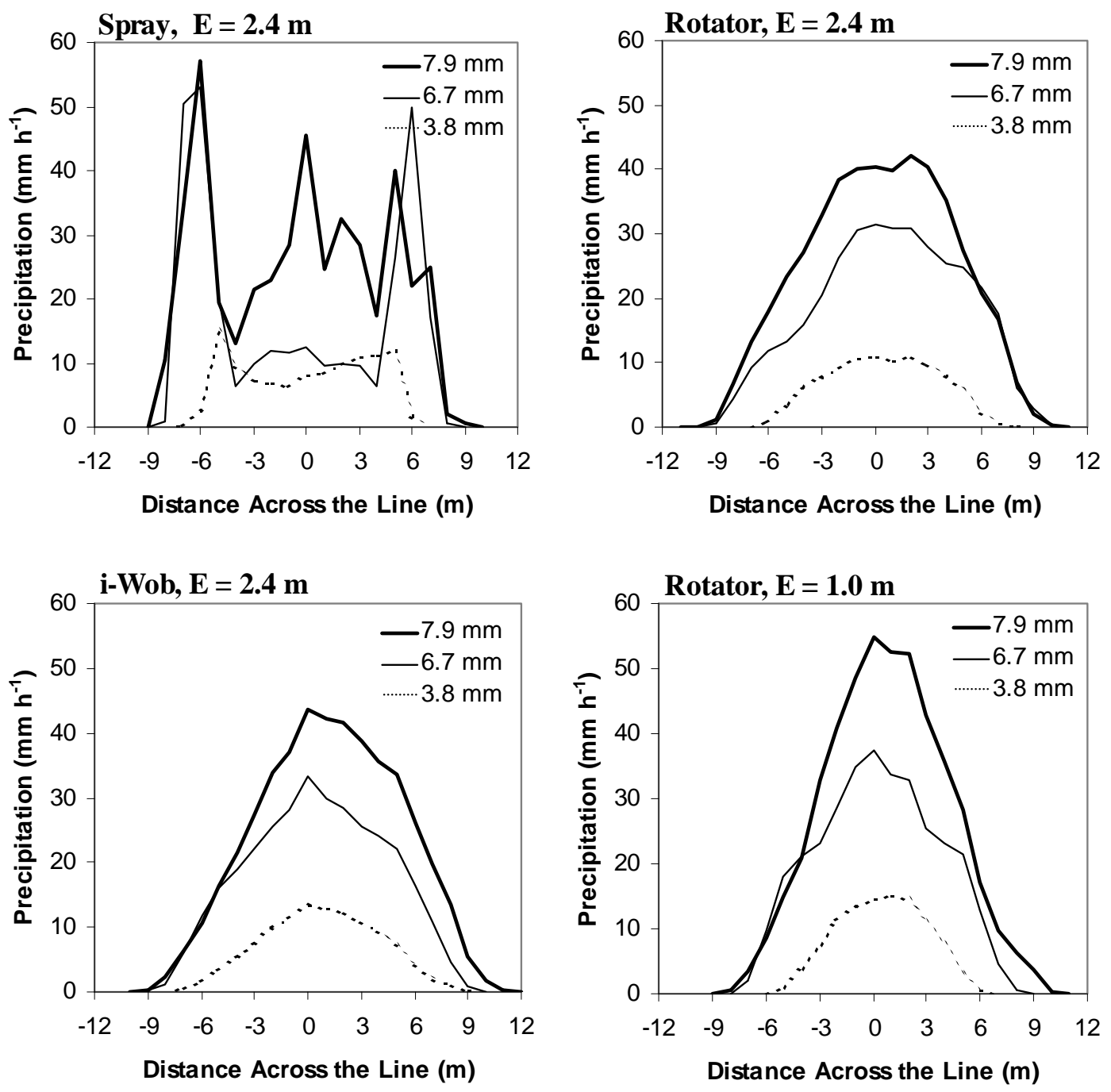
Figure 5. Simulated water application profiles for different combinations of type of sprinkler, spacing (S) and nozzle elevation (E). Results are presented for the three experimental nozzle diameters. The simulated machine speed was $30 \mathrm{~m} \mathrm{~h}^{-1}$.
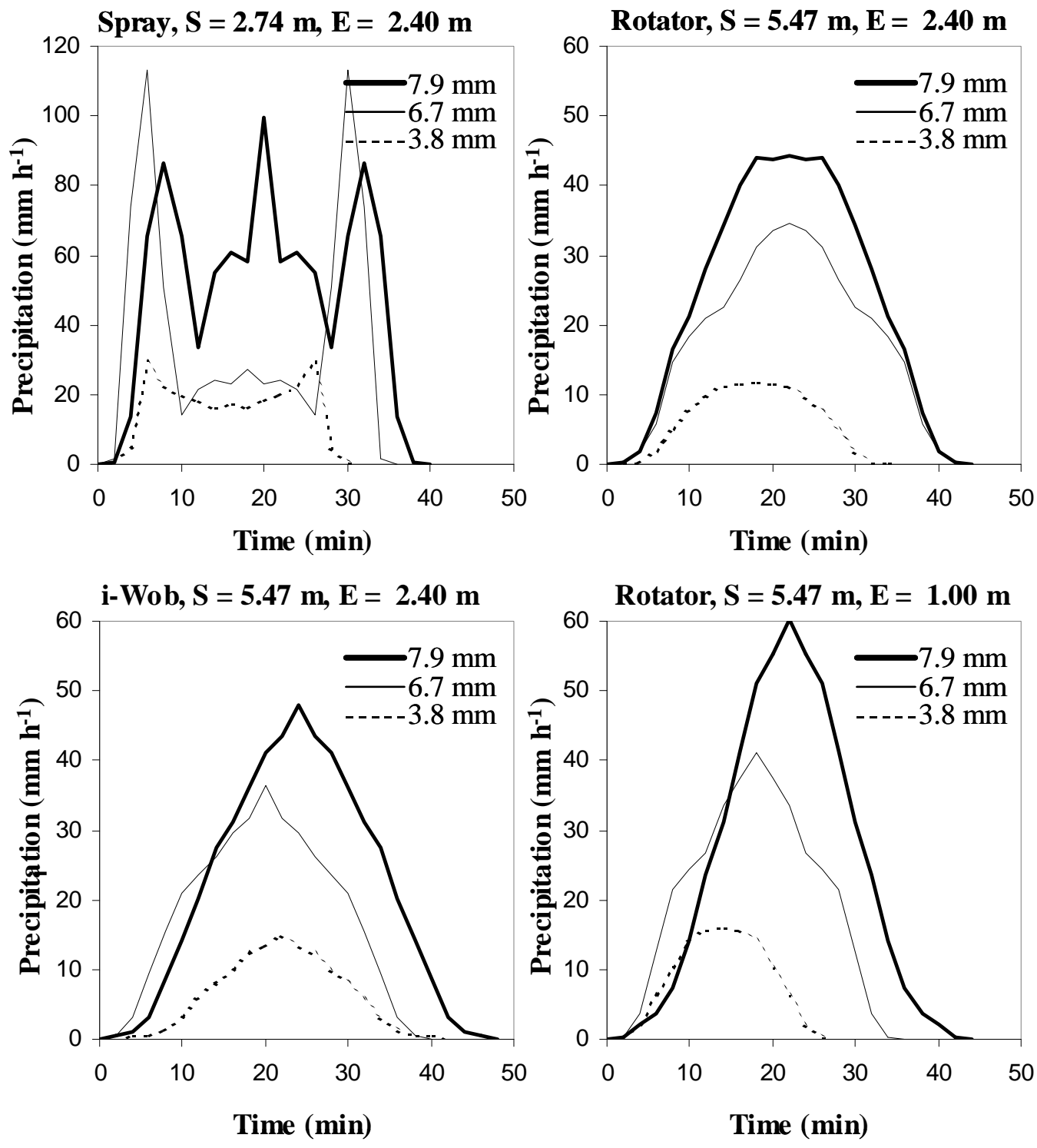
Figure 6. Wind Drift and Evaporation Losses (WDEL, \%) as a function of Wind Speed for the static experiments. Results are presented to compare: a) two nozzle elevations for Rotator sprinklers; and b) the three types of sprinklers using a nozzle elevation of $2.4 \mathrm{~m}$.
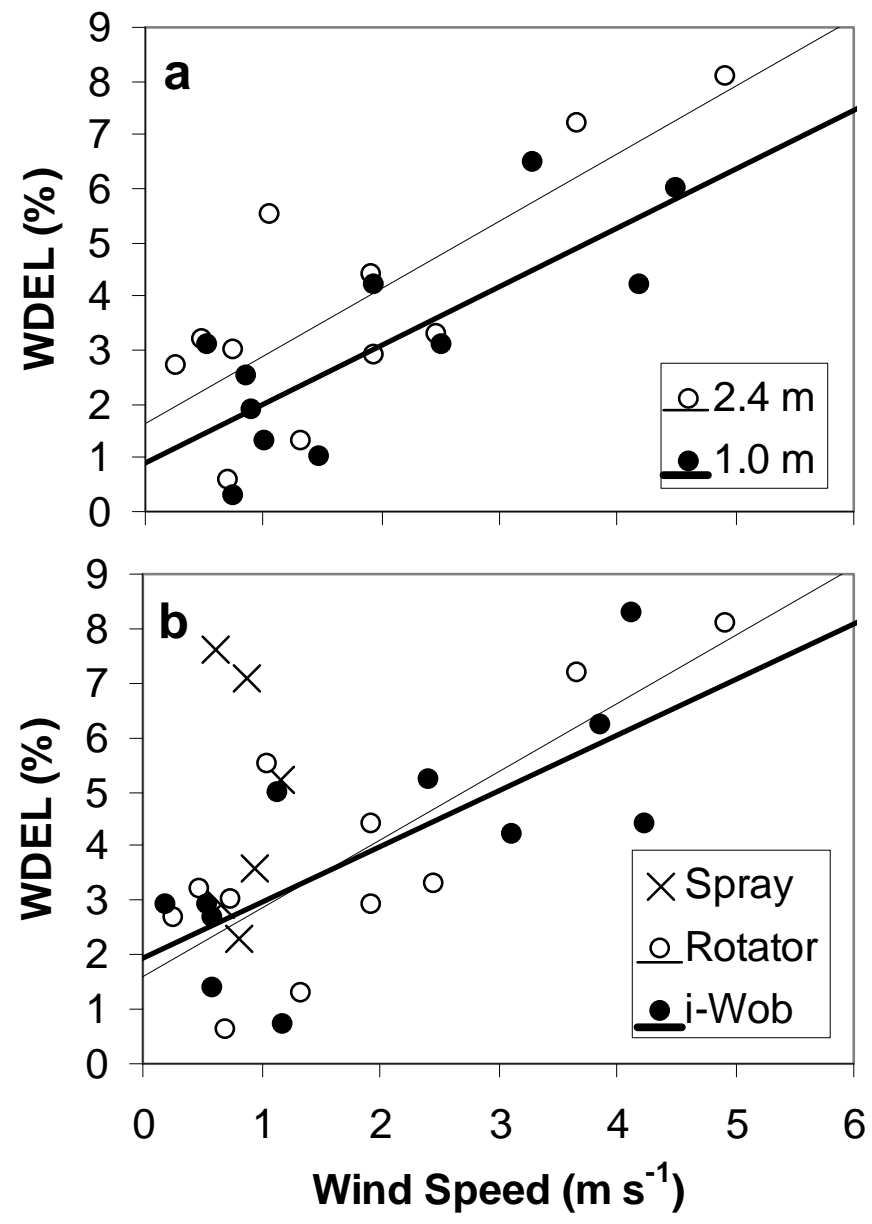
Figure 7. Water application profiles for a machine speed of $31.1 \mathrm{~m} \mathrm{~h}^{-1}$ derived from the static and dynamic experiments, for Spray, Rotator and i-Wob sprinklers equipped with $6.7 \mathrm{~mm}$ nozzles and located at an elevation of $2.4 \mathrm{~m}$ over the soil surface. For each type of spray sprinkler, the available static experiments with wind speeds lower than $1.5 \mathrm{~m} \mathrm{~s}^{-1}$ were averaged and the result was used for simulation purposes.
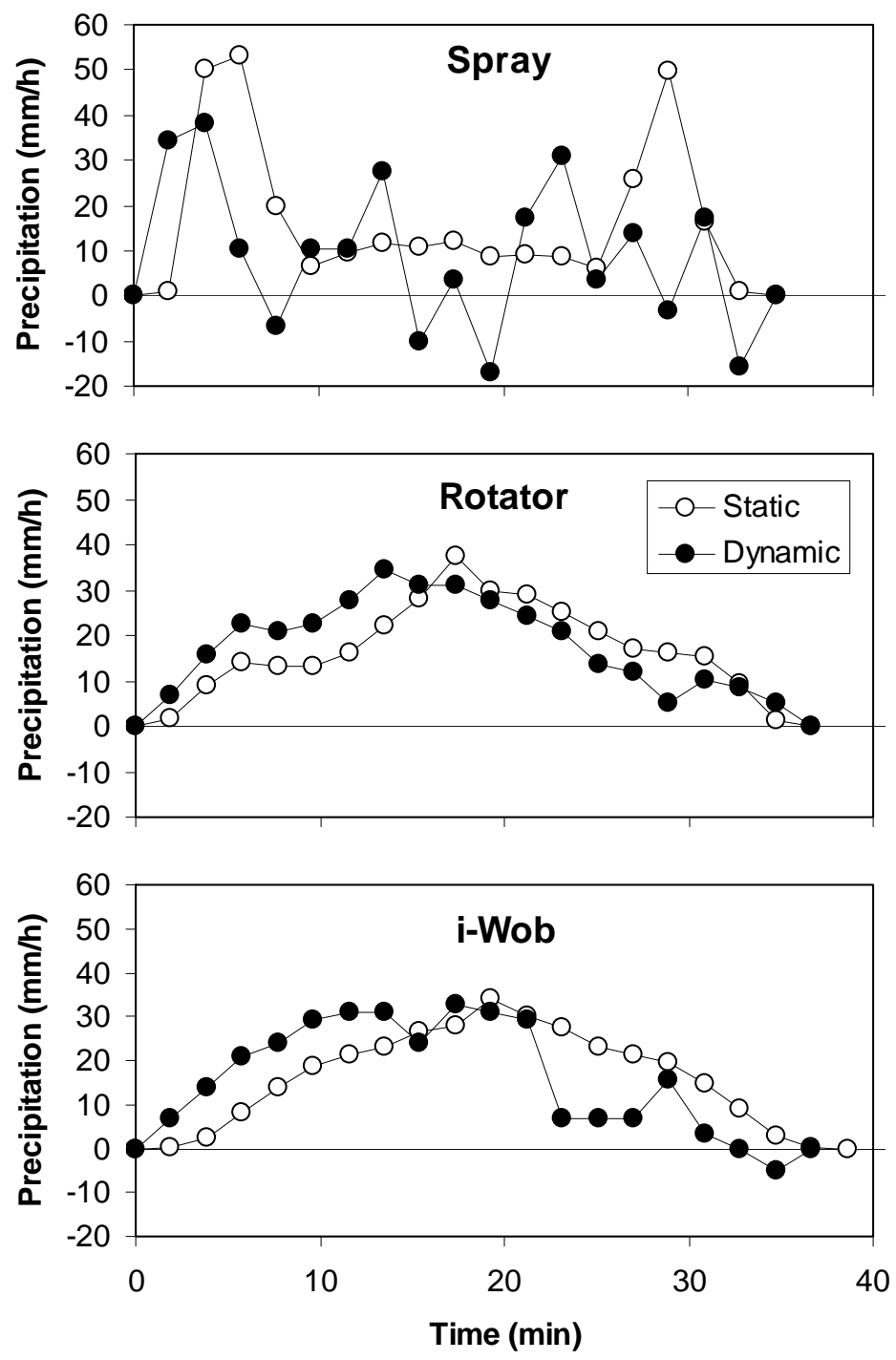